\title{
Progresif Maküler Hipomelanozis
}

\section{Progressive Macular Hypomelanosis}

\author{
İnci Mevlitoğlu, Caner Aykol
}

Selçuk Üniversitesi Meram Tıp Fakültesi, Deri ve Zührevi Hastalıklar Anabilim Dalı, Konya, Türkiye

\section{Özet}

Progresif maküler hipomelanozis (PMH) ilk olarak 1988 yılında Guillet tarafından tanımlanmıştır. PMH sıklıkla gövdeyi tutan, asemptomatik, zor fark edilen, numuler, skuamsız, hipopigmente maküllerle karakterizedir. PMH çoğunlukla adölesan ve genç kadınlarda görülür. Etyopatogenezi hala bilinmemektedir. Wood lambası altında hipopigmente maküllerde kırmızı foliküler florasan görünürken komşu normal deride florasan gözlenmez. PMH'nin histopatolojik bulguları genellikle non-spesifiktir, ancak hipopigmente maküllerin melanin içeriğinin normal deriye göre azalmıs olması sık görülen bir bulgudur. Etkili bir tedavi halen bilinmemektedir. Ancak fototerapi PMH'yi kontrol altına almada etkili bulunmuş olmasına karşın hastalığın rekürrensini önlememektedir. Biz bu makalede PMH'nin etyopatogenezi, klinik bulguları, histopatolojisi, ayırııı tanısı ve tedavi seçeneklerini derlemeyi amaçladık. (Türkderm 2011; 45: 62-5)

Anahtar Kelimeler: Progresif maküler hipomelanozis, pigmentasyon bozuklukları

\section{Summary}

Progressive macular hypomelanosis (PMH) was initially described and named by Guillet in 1988. PMH is characterized by asymptomatic, ill-defined, nummular, non-scaly, hypopigmented macules, localized predominantly on the trunk. PMH is mostly seen in adolescents and young females. The etiopathogenesis of PMH is still unknown. The red follicular fluorescence becomes visible in the hypopigmented macules under Wood's lamp but is absent in normal adjacent skin. The histopathologic findings in PMH are usually non-specific, but a common feature is the decreased melanin content in the hypopigmented macules compared to the normal skin. No effective therapy is currently known. Phototherapy was found to be effective for the control of $\mathrm{PMH}$; however, it does not prevent recurrence of the disease. In this paper, we aimed to review the etiopathogenesis, clinical findings, histopathology, differential diagnosis and treatment options of PMH. (Turkderm 2011; 45: 62-5)

Key Words: Progressive macular hypomelanosis, pigmentation disorders

\section{Giriş}

\section{Progresif Maküler Hipomelanozis}

Progresif maküler hipomelanozis (PMH) ilk kez 1988 yılında Guillet tarafından tanımlanmış zor fark edilen, numuler, hipopigmente maküllerle seyreden bir pigmentasyon bozukluğudur'. Lezyonlar sıklıkla gövde ön ve arka yüzüne yerleşir. Bazen boyun ve üst ekstre- mitelerin proksimal kısımları tutulabilir. Yüz tutulumu ise oldukça nadirdir. Eller ise hemen hiç tutulmayan bölgedir. Hipopigmente maküller Wood lambası altında incelendiğinde foliküler kırmızı floresan verirken normal deri floresan vermez. Geçmişte cutis trunci variata, creola diskromia, idiyopatik geniş maküler hipomelanozis, yaygın pitriazis alba gibi çok farklı isimlendirilen bu tablo günümüzde progresif maküler hipomelanozis şeklinde adlandırılmaktadır².

Yazıșma Adresi/Address for Correspondence: Dr. Inci Mevlitoğlu, Selçuk Ünivesitesi Meram Tıp Fakültesi, Deri ve Zührevi Hastalıklar Anabilim Dalı, 42100 Konya, Türkiye, Tel.: +90332 2236204 E-posta: drcaneraykol@gmail.com Geliş Tarihi/Received: 12.04.2011 Kabul Tarihi/Accepted: 19.04.2011

Türkderm-Deri Hastalıkları ve Frengi Arşivi Dergisi, Galenos Yayınevi tarafından basılmıştır

Turkderm-Archives of the Turkish Dermatology and Venerology, published by Galenos Publishing. 


\section{Etyopatogenez}

Progresif maküler hipomelanozisin etyopatogenezi hakkında pek çok hipotez öne sürülmüşse de etyopatogenez hala açık değildir.

Guillet, PMH tanısı alan hastaların ırk olarak miks etnisite (siyah ve beyaz ebeveynleri olan) gösterdiğini ve hastalığın oluşumunda miks etnik orjinin önemli olduğunu vurgulamışıı'. Ancak günümüzde miks etnisite göstermeyen pek çok $\mathrm{PMH}$ hastası tanımlanmıștı ${ }^{2,3}$.

Borelli ise cutis trunci variata olarak tanımladığı ancak bugün PMH olarak kabul edilen hastalığın aynı aile bireylerinde görülen bir genodermatoz olduğunu ileri sürmüştür4. Günümüzde pek çok çalışmada hastalarda hemen hiç aile öyküsünün olmaması bu hipotezi desteklememektedir.

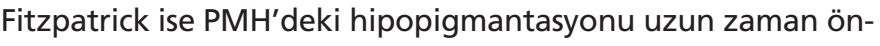
ce geçirilmiş ve kaybolmuş bir fungal infeksiyonun neden olduğu pigment değişikliklerine bağlamıştır ${ }^{5}$. Ancak PMH olgularında yapılan potasyum hidroksit $(\mathrm{KOH})$ incelemede ve biyopsi örneklerinde mantar hif ve sporlarına rastlanmamaktadı ${ }^{23,6}$.

Westerhof ise $\mathrm{PMH}$ patogenezinde propionibacterium türlerinin etkisi olduğunu ileri sürmüştür. Yaptıkları çalışmada 8 PMH hastasından 7 tanesinde lezyonel foliküler deride P.acnes varlığını göstermişlerdir. Nonlezyonel deri bölgesinde ise sadece 1 hastada P.acnes gösterilmiștir? . Wood ışığı muayenesindeki kırmızı foliküler floresan deride cornybacterium ve propionibacterium türlerinin varlığına işaret eder. Bu bakterilerin ürettiği porfirinler UV ışını altında kırmızı görünür. Özellikle bu bakterilerin neden olduğu kırmızı foliküler floresanın PMH lezyonlarında gözlenmesi ve hastaların çeşitli topikal antibakteriyel ajanlardan fayda gördüğünün bildirilmesi etyolojide P.acnes'in sorumlu olabileceğini düşündürmektedir². Ancak akne vulgaris hastalarında hipopigmentasyonun görülmemesi, nedenin başka bir tür bakteri olabileceği sorusunu akla getirmektedir. Bu amaçla Relyveld ve arkadaşları amplifiye fragman uzunluk polimorfizm tekniği kullanarak yaptıkları çalışmada 14 PMH hastasından 8'inde akne vulgarisde görülen P.acnes'den farklı, daha önceden tanımlanmamış bir propionibacterium türü varlığını göstermişler ve $\mathrm{PMH}$ gelişiminde rollerinin açıklığa kavuşması için daha ileri çalışmalara ihtiyaç olduğunu vurgulamışlardır.

\section{Epidemiyolojik ve Klinik Özellikler}

Hastalığın prevalansı tam olarak bilinmemektedir. Sıklıkla diğer hipopigmentasyon ile seyreden (pitriazis versikolor gibi) hastalıklarla karıştırılarak yanlış tanı alır. Koyu tenli kişilerin yoğun olduğu coğrafyalarda, hipopigmente maküller daha kolay fark edildiğinden bu bölgelerde daha sık tanı alı2 ${ }^{2,3}$. Guillet tarafından Fransa'dan tanımlanan tüm hastalar miks etnik orjinli hastalardır'. Avrupa'dan Hollanda ${ }^{2}$, Almanya ${ }^{9}$ ve Türkiye'den ${ }^{10}$ bildirilen olgularda ise belirgin bir etnik özellik

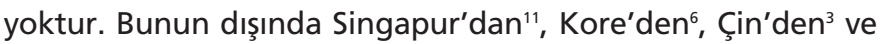
Brezilya'dan da' ${ }^{12}$ olgu bildirilmiştir. Kadın/erkek oranı, Hollanda Pigmentasyon Bozuklukları Enstitü'sünde takip edilen 291 hastada 7/1 olarak bildirilmiştir ${ }^{2}$. Hwang ${ }^{6}$ ve Duarte ${ }^{12}$ yaptıkla- rı çalıșmalarda kadınlarda 3 kat daha fazla görüldüğünü bildirmişlerdir. Kumarasinghe ve arkadaşları ise yaptıkları çalışmada kadın/erkek oranını eşit bulmuşlardır"1. Hastalık 13-45 yaş aralığında görülebilse de hastaların çok büyük bir bölümü 20 'li yaşlardadır. Ortalama yaş değişik çalışmalarda 23,8 - 26,5 arasında bildirilmektedir ${ }^{2,3,6,11,13}$. Sonuç olarak PMH adölesan ve genç erişkin dönemde daha sık görülen ve kadınları daha çok etkileyen bir hastalık olarak kabul edilebilir.

Progresif maküler hipomelanozisin temel klinik özelliği hipopigmente, numuler, belli belirsiz, üzerinde skuam bulunmayan maküllerdir (Resim 1). Özellikle gövde ön ve arka yüzüne yerleşirken, boyun ve üst ekstremitelerin proksimal kısımları da etkilenebilir. Zamanla hipopigmente maküller konfluent bir hal alabilir. Lezyonlarda kaşıntı, ağrı, disestezi gibi herhangi bir subjektif semptom bulunmaz. Hastaların öyküsünde daha önce geçirilmiş herhangi bir inflamatuvar dermatoz öyküsü yoktur. Asemptomatik lezyonlar sadece kozmetik sorun teşkil eder. Bazı hastalar tarafından ise hiç fark edilmeyebilir $2,3,13$.

\section{Tanı}

Hastalığın tanısında klinik bulguların yanısıra hipopigmente maküllerle karakterize diğer dermatozların ekarte edilmesi oldukça önemlidir. Wood lambası muayenesi, histopatoloji, immünohistokimyasal çalışmalar, konfokal lazer scanning mikroskobi ve elektron mikroskobik inceleme tanıya yardımcı olabilir.

Wood Lambası Muayenesi: Wood lambası altında PMH lezyonları daha belirginleşirken lezyonlarda foliküler kırmızı floresan dikkat çeker. Sağlam deride ise floresan izlenmez.

Histopatoloji: Histopatolojik bulgular nonspesifiktir. Sağlam komşu deri ile hipopigmente maküller histopatolojik olarak karşılaştıııldığında tek farklıığın hipopigmente maküllerde epidermal melanin içeriğinin komșu sağlam deriye oranla azalmış olmasıdır. Dermis genellikle normal görünümdedir². Wu ve arkadaşları yaptıkları çalışmada dermisin superfisyal kı-

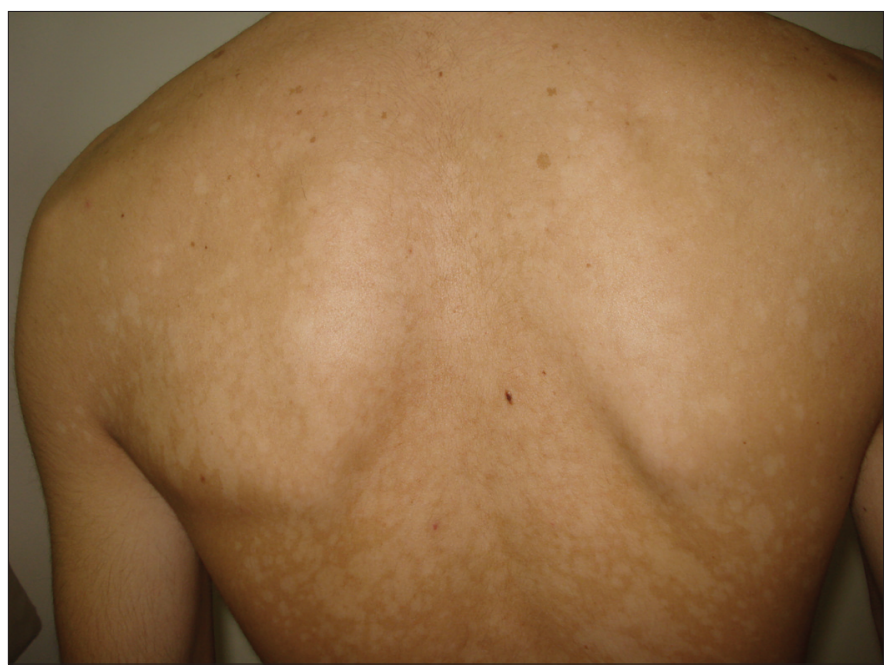

Resim 1. Gövde arka yüzde yaygın, konfluent, skuamsız, hipopigmente maküller 
sımlarında nadiren lenfositik infiltrasyona rastlamışlardır ${ }^{3}$. Spongiozis gibi ekzamatöz infiltrasyon bulguları, atipik lenfositik infiltrasyon, epidermotropizm ve mantar spor ile hifalarına histopatolojik kesitlerde rastlanmaz². Lezyonal deride pilosebase üniteyi içeren kesitlerde Gram boyama yapıldığında Gram (+) bakteriler gösterilebilir?

İmmünohistokimya: Yapılan çalışmalarda hipopigmente maküller ile komşu sağlam deri, melanosit morfolojileri ve sayıları bakımından immunhistokimyasal olarak S-100 boyama ile karşılaştırıldığında anlamlı fark bulunmamıştır ${ }^{6,11}$. Wu ve arkadaşları S-100 boyası melanositlere spesifik olmadığından immunhistokimyasal olarak S-100 yanında tirozinaz related protein 1 (TRP-1) ve tirozinaz (T311) boyaları da kullanmışlar ancak her üç boyamada da normal deri ile karşılaştırıldığında hipopigmente maküllerde melanosit sayısı ve morfolojisi açısından istatistiksel olarak anlamlı fark saptamamışlardır³.

Konfokal Lazer Scanning Mikroskobi: Hipopigmente alanlar konfokal lazer scanning mikroskobi ile incelendiğinde dermal papilla etrafında sağlam bir pigment halkası görülmektedir. Ancak, çevreleyen normal deri ile karşılaştırıldığında melanin içeriği azalmıştır ${ }^{3}$.

Elektron Mikroskobik İnceleme: PMH lezyonları elektron mikroskobik olarak normal deri ile karşılaştırıldığında içerdikleri melanozomların daha küçük ve daha erken evrede (evre II-III) olduğu ve membranla çevrili gruplar şeklinde kümelendiği gözlenmektedir. Bu bulgular Fitzpatrick deri tipi V ve VI olan hastalarda deri tipi III ve IV olan hastalara göre çok daha belirgindir ${ }^{2,13}$.

\section{Ayırıcı Tanı}

Ayırıcı tanıda diğer edinsel hipopigmentasyonla seyreden hastalıklar düşünülmelidir. En çok karışan hastalıklar; pitriazis versikolor, postinflamatuvar hipopigmentasyon, pitriazis alba, lepra ve hipopigmente mikozis fungoidestir. Pitriazis versikolor lezyonlarının sınırları daha belirgindir ve lezyonlar daha asimetrik yerleşir. Üzerinde ince skuamlar bulunabilir. Wood lambası muayenesinde sarı floresan verir. $\mathrm{KOH}$ inceleme, mantar kültürü ve biyopsi materyallerinde mantar hif ve sporlarına rastlanır. Postinflamatuvar hipopigmentasyonda önceden geçirilmiş bir inflamatuvar dermatoz öyküsü vardır. Pitriazis alba lezyonları sıklıkla çocuklarda ve yüz ile ekstremitelerde yerleşir. Lezyonlarda ince beyaz skuamlar bulunabilir. Hastalarda sıklıkla atopi öyküsü mevcuttur. Lepra hastalarında lezyonlara duyu kusuru eşlik edebilir. Hipopigmente mikozis fungoideste ise histopatolojik olarak epidermotropizm ve atipik lenfositik infiltrasyon tipiktir. Lezyonlar kaşıntılı olabilir².

\section{Tedavi}

PMH için günümüzde, etkili ve kabul görmüş bir tedavi protokolü bulunmamaktadır. Tedavide bugüne kadar sistemik ve topikal antifungaller, topikal steroidler, topikal ve sistemik antibakteriyel ajanlar ile PUVA ve darbant UVB gibi ultraviyo- le tedavileri denenmiştir. Özellikle topikal ve sistemik antifungal ajanlar ile topikal steroidler etkisiz bulunurken, ultraviyole tedavileri ve ultraviyole ile topikal antibakteriyel kombinasyonlarından başarılı sonuçlar alınmıştır ${ }^{2,6}$.

Yapılan bir çalışmada PUVA tedavisi ve $\% 5$ benzoil peroksit I $\% 1$ klindamisin losyon kombinasyonu ile PUVA ve \%0,005 flutikazon propionat krem kombinasyonu 14 hafta boyunca uygulanmış ve PUVA + antibakteriyel kombinasyonu PUVA + antiinflamatuvar kombinasyonuna göre anlamlı şekilde üstün bulunmuştur. PUVA hastalığın tedavisinden çok repigmentasyonu hızlandırmakta, antibakteriyel ajanlar ise patogenezde sorumlu tutulan propionibacteriumların neden olduğu inhibisyonu ortadan kaldırmaktadır ${ }^{14}$.

Chung ve arkadaşları 20 seans darbant UVB ile PMH'li bir hastayı başarıyla tedavi etmişler ve hastada rekürrens gözlememişlerdir ${ }^{15}$. Erpolat ve arkadaşları ise bir PMH olgusunu darbant UVB + \%1 topikal klindamisin losyon kombinasyonu ile başarılı bir şekilde tedavi etmişlerdir ${ }^{10}$. Wu ve arkadaşları darbant UVB + benzoil peroksit kombinasyonunu bir PMH hastasında uygulamışlar ve etkili bulmuşlardır ${ }^{16}$. Sim ve arkadaşları darbant UVB ile darbant UVB + topikal antibakteriyel ajan (benzoil peroksit/klindamisin) kombinasyonunu karşılaştırmışlar ve kombine terapinin darbant UVB'nin tek başına kullanımına üstün olmadığını saptamışlardır ${ }^{17}$. Kwah ve arkadaşları ortalama 27 seans darbant UVB tedavisi verdikleri 6 hastayı tedavi etmişler ancak tedavi sonlandırıldıktan sonra 3 hastada nüks görmüşlerdir. En erken nüks tedavi sonrası 4. haftada gelişmiştir ${ }^{18}$.

PMH tedavisinde PUVA ile darbant UVB'nin karşılaştırıldığı 84 hastalık bir çalışmada, her iki tedavi de etkili bulunmuş ancak etkinlik bakımından her iki grupta istatistiksel olarak anlamlı bir fark tespit edilmemiştir. Darbant UVB daha az yan etki potansiyeline sahip olduğundan tedavide PUVA'ya tercih edilebileceği vurgulanmıştır. Aynı çalışmada fototerapinin $\mathrm{PMH}^{\prime} \mathrm{yi}$ kontrol altına alabildiği ama hastalığın rekürrensi üzerine etkisi olmadığı bildirilmiştir ${ }^{12}$.

Farklı tedavi seçeneklerinin kullanıldığı 20 hastadan oluşan bir çalışmada ise 7 hastaya çeşitli topikal tedaviler (4 hastaya topikal kortikosteroid, 2 hastaya topikal tretinoin, 1 hastaya topikal pimekrolimus), 6 hastaya darbant UVB, 4 hastaya oral minosiklin verilmiş, 3 hasta ise tedavisiz takip edilmiştir. Darbant UVB uygulanan tüm hastalarda klinik iyileşme görülmüştür. Topikal tedavi verilen hastalardan ise yalnız \%1 hidrokortizon losyon ile tedavi edilen bir hastada başarılı sonuç alınmıştır. Oral minosiklin kullanan hastalardan bir hastada klinik yanıt alınmıştır. Tedavisiz takip edilen hastalardan ise yalnız birinde yaklaşık 8,3 yıl sonra spontan repigmentasyon görülmüştür ${ }^{6}$.

Sonuç olarak PMH tedavisinde fototerapi, hastalığın rekürrensi üzerine etkisi olmamasına karşın bugün için tedavi seçenekleri arasında ilk sırada görünmektedir. Topikal antibakteriyel ajanlar dışında diğer topikal tedavi seçenekleri etkili değildir. Gelecekte, hastalığın patogenezinin daha net ortaya konması daha efektif tedavi seçeneklerinin geliştirilmesinde yol gösterici olacaktır. 


\section{Kaynaklar}

1. Guillet $G$, Helenon R, Gauthier $Y$, Surleve-Bazeille JE, Plantin P, Sassolas B: Progressive macular hypomelanosis of the trunk: primary acquired hypopigmentation. J Cutan Pathol 1988;15:286-9.

2. Relyveld GN, Menke HE, Westerhof W: Progressive macular hypomelanosis: an overview. Am J Clin Dermatol 2007;8:13-9.

3. Wu XG, Xu AE, Song $X Z$, Zheng JH, Wang $P$, Shen $H$ : Clinical, pathologic, and ultrastructural studies of progressive macular hypomelanosis. Int J Dermatol 2010;49:1127-32.

4. Borelli D: [Cutis "trunci variata." A new genetic dermatosis]. Med Cutan Ibero Lat Am 1987;15:317-9.

5. Fitzpatrick TB. In: Sober AJ, Fitzpatrick TB, editors: Yearbook of dermatology. St Louis (MO): Mosby-Year Book, 1996:416-7.

6. Hwang SW, Hong SK, Kim SH et al: Progressive macular hypomelanosis in korean patients: a clinicopathologic study. Ann Dermatol 2009;21:261-7.

7. Westerhof W, Relyveld GN, Kingswijk MM, de Man P, Menke HE: Propionibacterium acnes and the pathogenesis of progressive macular hypomelanosis. Arch Dermatol 2004;140:210-4.

8. Relyveld GN, Westerhof W, Woudenberg J et al: Progressive macular hypomelanosis is associated with a putative Propionibacterium species. J Invest Dermatol 2010;130:1182-4.

9. Neynaber S, Kirschner C, Kamann S, Plewig G, Flaig MJ: Progressive macular hypomelanosis: a rarely diagnosed hypopigmentation in Caucasians. Dermatol Res Pract 2009;2009:607682.

10. Erpolat S, Gorpelioglu C, Sarifakioglu E: A case of progressive macular hypomelanosis treated with $1 \%$ topical clindamycin lotion and narrow-band ultraviolet B. Photodermatol Photoimmunol Photomed 2010;26:277-8.
11. Kumarasinghe SP, Tan SH, Thng S, Thamboo TP, Liang $S$, Lee YS: Progressive macular hypomelanosis in Singapore: a clinico-pathological study. Int J Dermatol 2006;45:737-42.

12. Duarte I, Nina BI, Gordiano MC, Buense R, Lazzarini R: Progressive macular hypomelanosis: an epidemiological study and therapeutic response to phototherapy. An Bras Dermatol 2010;85:621-4.

13. Relyveld GN, Dingemans KP, Menke HE, Bos JD, Westerhof $\mathrm{W}$ : Ultrastructural findings in progressive macular hypomelanosis indicate decreased melanin production. J Eur Acad Dermatol Venereol 2008;22:568-74.

14. Relyveld GN, Kingswijk MM, Reitsma JB, Menke HE, Bos JD, Westerhof W: Benzoyl peroxide/clindamycin/ultraviolet $A$ is more effective than fluticasone/ultraviolet $A$ in progressive macular hypomelanosis: a randomized study. J Am Acad Dermatol 2006;55:836-43.

15. Chung YL, Goo B, Chung WS, Lee GS, Hann SK: A case of progressive macular hypomelanosis treated with narrow-band UVB. J Eur Acad Dermatol Venereol 2007;21:1007-9.

16. Wu XG, Xu AE, Luo XY, Song XZ: A case of progressive macular hypomelanosis successfully treated with benzoyl peroxide plus narrow-band UVB. J Dermatolog Treat 2010;21:367-8.

17. Sim J, Lee D, Lee J, Kim Y: Comparison of the clinical efficacy of NBUVB and NBUVB with benzoyl peroxide/clindamycin in progressive macular hypomelanosis. J Eur Acad Dermatol Venereol 2011. [Epub ahead of print].

18. Kwah YC, Chong WS, Thiam-Seng Theng C, Goh BK: Treatment of progressive macular hypomelanosis with narrow-band ultraviolet B phototherapy. Photodermatol Photoimmunol Photomed 2010;26:153-5. 